Research Report

\title{
ASSOCIATION OF TOBACCO SMOKING WITH BIPOLAR AFFECTIVE DISORDER- A COMPARATIVE CROSS-SECTIONAL STUDY AT A TERTIARY CARE CENTRE IN SOUTH INDIA
}

\author{
Parvathy Radhakrishnan ${ }^{1}$, Praveen Arathil ${ }^{*}$, Dinesh Narayanan ${ }^{2}$ \\ ${ }^{1}$ Sree Narayana Institute of Medical Sciences, Kochi, Kerala \\ ${ }^{2}$ Amrita Institute of Medical Sciences, Kochi, Kerala \\ *Corresponding address: Department of Psychiatry, Amrita Institute of Medical Sciences, Ponekkara PO, Kochi-682041. Email: \\ praveen.arathil@gmail.com
}

\section{ABSTRACT}

Background: Smokers with psychiatric disorders, most notably those with serious mental illness and substance use disorders tend to present with more severe nicotine dependence and nicotine withdrawal than smokers without these illnesses. The following study aims to explore the correlation of smoking with bipolar affective disorder

Setting and design: The comparative cross-sectional study was done in Amrita Institute of Medical Sciences \& Research Centre, Kochi, a 1,450-bed hospital for a period of 2 years.

Methods and materials: Seventy subjects with Bipolar affective Disorder who were in remission for at least two months and Seventy subjects who were relatives of paediatric outpatients were included in the study and control group, respectively. Clinical variables were assessed, and Hamilton depression rating scale, Young mania rating scale and Fagerstorm nicotine rating scale were administered to the subjects.

Results:_In this study, $52.9 \%$ of subjects with bipolar disorder were found to be smokers, and $51.4 \%$ of the normal population were smokers. No significant association was observed between bipolar affective disorder, and smoking tobacco, however, a significant correlation was found between smoking status and the total number of episodes of the disorder, psychotic episodes and suicide attempts.

Conclusion: There appears to be a relationship between smoking tobacco and certain clinical features of bipolar affective disorder. It is possibly a bidirectional relation between these two disorders.

Keywords: bipolar affective disorder, tobacco

\section{INTRODUCTION}

Smoking tobacco continues to be the most significant yet preventable cause of death and disability. ${ }^{1}$ Higher rate of tobacco dependency has been reported among individuals with mental disorders than among patients with physical illnesses and the general population. Multiple co-morbidities often accompany the bipolar disorder, but substance abuse is particularly common, and its co-occurrence often leads to a more pernicious and difficult to treat course of illness. ${ }^{2}$

\footnotetext{
Access the article online:

https://kjponline.com/index.php/kjp/article/view/215 DOI: https://doi.org/10.30834/KJP.33.2.2020.215

Recieved:19/09/20. Web publication: 31/10/2020
}

The co-existence of substance misuse and psychiatric disorders is often referred to by the term 'dual diagnosis'. Instead of being perceived as a difficult to manage group, and perhaps untreatable, those with the dual diagnosis should be considered as needing more care and vulnerable group. Only a few studies examined this issue among bipolar affective disorder patients, and the findings were equivocal despite the known

How to cite the article: Radhakrishnan P, Arathil P, Narayanan D. Association of tobacco smoking with bipolar affective disorder- a comparative cross-sectional study at a tertiary care centre in south India. Kerala Journal of Psychiatry 2020, 33(2):131-136. 
association between smoking and psychotic symptomatology in schizophrenia. ${ }^{3}$

This elevated smoking rate may not only influence the course of the disorder but may also contribute to higher levels of tobacco-related morbidity and mortality. ${ }^{4}$ The high prevalence rates of smoking among individuals with bipolar disorder appear to be attributable to both increased likelihood of initiating smoking and decreased likelihood of successfully quitting. One potential explanation for the high rate of smoking among individuals with bipolar disorder is that bipolar symptoms may increase the risk of initiating or maintaining regular smoking and bipolar disorder and smoking may also be linked through common risk factors, including both genetic and environmental influences. Cigarette smokers may require as much as a $50 \%$ increased dose of antipsychotics and antidepressants to gain symptom relief. If tobacco use is not considered when establishing a dosing regimen for medications that interact with tobacco smoke, treatment outcomes may be worsened. Smokers with psychiatric disorders most notably those with serious mental illness tend to present with more severe nicotine dependence and nicotine withdrawal than smokers without these illnesses. ${ }^{5}$

Hence management of patients with dual diagnosis is a challenge. Given this, the following study primary objective was to explore the association of smoking with bipolar disorder with the normal population. Also, the investigators planned to assess the correlation of smoking tobacco with previous suicide attempts and number of episodes with psychotic symptoms in subjects with bipolar affective disorder.

\section{MATERIALS AND METHODS}

The study was done in Amrita Institute of Medical Sciences \& Research Centre, Kochi, a 1,450-bed hospital. The study was conducted for two years, from 2013 to 2015 in the outpatient department of Psychiatry._Based on the prevalence of smoking in subjects with Bipolar affective Disorder in a previous study, with 95\% confidence and $90 \%$ power minimum sample size comes up to 70 each in the two groups. ${ }^{6}$ Subjects included in the study were those attending the outpatient office in the department of psychiatry, who was diagnosed with bipolar affective disorder by a consultant psychiatrist in the institute, using ICD-10 Criteria and were in remission for at least two months so that substance abuse as part of mood episode were excluded. ${ }^{7}$ For the comparison group, relatives of paediatric outpatients who self-declared as not being aware of currently having any psychiatric disorder were selected. They also had to have the ability to read and write English or Malayalam. Those subjects who had lack of willingness or capacity to provide informed consent to participate in the study or those who had other known comorbid psychiatric disorders other than substance abuse disorder or who were not able to complete the assessment were excluded from the study.

A semi-structured proforma was used to record information regarding the sociodemographic profile $\&$ clinical details of the subjects. Hamilton depression rating scale (HAMD) was used for assessing the presence of depressive symptoms. It is a multiple item questionnaire published by Max Hamilton in 1960, used to indicate depression, and as a guide to evaluating recovery. It is a validated scale used in India used to assess depressive symptoms in bipolar disorder. Its internal reliability is adequate. ${ }^{8}$ Young mania rating scale (YMRS) was used to assess for the presence of manic symptoms. It is a validated instrument used most frequently for rating mania symptoms. The scale has 11 items and is based on the patients' subjective report of his or her clinical condition over the previous 48 hours.' Fagerstrom test for nicotine dependence (FND) a standard validated instrument was used for assessing the intensity of physical addiction. It helps to document the indication for prescribing medication for nicotine withdrawal. The questionnaire contains six items. Scores under 5 indicate that nicotine dependence is low, 5 to 7 indicate moderate dependence, and above 7 suggests high nicotine dependence. The internal consistency of the scale was found to be high. ${ }^{10}$

The ethics committee approved the study. Convenience sampling method was used to select the subjects. Written informed consent was taken from the patients after explaining the details of the study. Sociodemographic data were recorded using semistructured proforma. Clinical variables were also recorded from the subjects.

STATISTICAL ANALYSIS

Statistical analysis was done using IBM SPSS Statistics v20 for Windows (SPSS Inc., Chicago, U.S.A.). To test 
the statistical significance of the association of smoking status with bipolar affective disorder and for the association of suicidal attempts with smoking in the bipolar group, the chi-square test was applied. For the association of total episodes of the disorder, previous episodes with psychotic symptoms and episodes requiring hospitalisation with smoking, Mann Whitney $\mathrm{U}$ test was used. The correlation of smoking with abuse of other psychoactive substances and the presence of any chronic medical illness in the two groups were computed using point biserial correlation. The biserial correlation was also used to calculate the correlation between smoking and rapid cycling in subjects with bipolar affective disorder. An independent t-test was used to compare years of tobacco use in two groups.

\section{RESULTS}

Table 1 shows the frequency distribution of the various sociodemographic data for the two groups, among 70 subjects with bipolar affective disorder, $61.4 \%$ were males while comparison group constituted $55.7 \%$ males. Distribution of Marital status of subjects in the two groups showed $10 \%$ were divorced or separated, and none of the subjects in the control group was divorced or separated. The distribution of occupational status showed $2.9 \%$ were unemployed among subjects with bipolar disorder, and none of the subjects in the control group was unemployed.

There was no association between smoking and bipolar disorder $(\mathrm{p}=0.866) .37$ (52.9\%) of subjects with bipolar disorder and 36 (51.4\%) of the normal population were smokers, respectively. The correlation between Fagerstrom nicotine scale score and use of other psychoactive substances (UPS) in subjects smoking tobacco with bipolar disorder $(\mathrm{r}=0.2, \mathrm{p}=0.23)$, and in subjects smoking in the control group $(\mathrm{r}=-0.01$, $\mathrm{p}=0.968)$ with point biserial correction did not show any significant correlation.

Correlation of Fagerstrom nicotine scale score and rapid cycling (RC) and chronic medical illness (CMI) in subjects with bipolar disorder showed no statistical significance. (Table 2)

Table 3 shows the correlation of smoking with total episodes of bipolar Disorder (TE), episodes with psychotic symptoms (EWPS) and episodes requiring hospitalisation (ERH) in subjects with bipolar disorder $(\mathrm{n}=70)$; the correlations were significant.

Table 4 shows that the correlation of smoking with previous suicide attempts in subjects with bipolar disorder failed to reach statistical significance at $P<0.05$.

Table 5 shows that there is a significant difference in years of tobacco use in the two groups.

Table 1. Frequency distribution table for sociodemographic variables in subjects with bipolar disorder) and control group

\begin{tabular}{|c|c|c|c|}
\hline Variable & Variable & $\begin{array}{l}\text { Bipolar } \\
\text { Group } \\
(n=70)\end{array}$ & $\begin{array}{c}\text { Normal } \\
\text { Population } \\
(\mathrm{n}=70)\end{array}$ \\
\hline \multirow{3}{*}{ Gender } & Male & $43(61.4 \%)$ & $39(55.7 \%)$ \\
\hline & Female & $27(38.6 \%)$ & $31(44.3 \%)$ \\
\hline & Nuclear & $47(67.1 \%)$ & $42(60 \%)$ \\
\hline \multirow{5}{*}{$\begin{array}{l}\text { Type of } \\
\text { family }\end{array}$} & Joint & $7(10.0 \%)$ & $6(8.6 \%)$ \\
\hline & 3 generation & $13(18.6 \%)$ & $22(31.4 \%)$ \\
\hline & Others & $3(4.3 \%)$ & $0(0)$ \\
\hline & Single & $6(8.6 \%)$ & $3(4.3 \%)$ \\
\hline & married & $52(74.3 \%)$ & $61(87.1 \%)$ \\
\hline \multirow{3}{*}{$\begin{array}{l}\text { Marital } \\
\text { status }\end{array}$} & Widowed & $5(7.1 \%)$ & $6(8.6 \%)$ \\
\hline & $\begin{array}{l}\text { Divorced/ } \\
\text { Separated }\end{array}$ & $7(10.0 \%)$ & $0(0 \%)$ \\
\hline & Degree or above & $31(44.3 \%)$ & $31(44.3 \%)$ \\
\hline \multirow{3}{*}{$\begin{array}{l}\text { Educational } \\
\text { status }\end{array}$} & Secondary & $34(48.6 \%)$ & $31(45.7 \%)$ \\
\hline & Primary & $5(7.1 \%)$ & $8(11.4 \%)$ \\
\hline & professional & $35(50 \%)$ & $30(44.3 \%)$ \\
\hline \multirow{5}{*}{$\begin{array}{l}\text { Occupation } \\
\text { al status }\end{array}$} & $\begin{array}{l}\text { Semi-skilled } \\
\text { worker }\end{array}$ & $13(18.6 \%)$ & $27(38.5 \%)$ \\
\hline & unskilled & $1(1.4 \%)$ & $9(12.9 \%)$ \\
\hline & unemployed & $2(2.9 \%)$ & $0(0 \%)$ \\
\hline & Self employed & $0(0 \%)$ & $4(4.3 \%)$ \\
\hline & $\begin{array}{l}\text { Home } \\
\text { maker/student }\end{array}$ & $19(27.1 \%)$ & $0(0 \%)$ \\
\hline \multirow{2}{*}{$\begin{array}{l}\text { Total } \\
\text { family } \\
\text { income per } \\
\text { month }\end{array}$} & $<19575$ & $31(44.3 \%)$ & $37(52.9 \%)$ \\
\hline & 7323-19575 & $39(55.7 \%)$ & $33(47.1 \%)$ \\
\hline \multirow{3}{*}{$\begin{array}{l}\text { Area of } \\
\text { residence }\end{array}$} & Rural & $15(21.4 \%)$ & $19(27.2 \%)$ \\
\hline & Urban & $18(25.7 \%)$ & $22(31.4 \%)$ \\
\hline & Suburban & $37(52.9 \%)$ & $29(41.4 \%)$ \\
\hline
\end{tabular}

Table 2 The correlation of Fagerstrom nicotine scale score with rapid cycling, and chronic medical illness in subjects with bipolar disorder $(\mathrm{n}=37)$

\begin{tabular}{lll}
\hline Variable & r value & p-value \\
\hline Rapid Cycling & 0.12 & 0.489 \\
Chronic medical Illness & +0.2 & 0.231 \\
\hline
\end{tabular}

coefficient $\mathrm{r}=$ point biserial correlation 


\section{DISCUSSION}

This study was undertaken with the background awareness that the high prevalence rates of smoking among individuals with bipolar disorder leads to both decreased likelihood of successfully quitting smoking tobacco and the difficulty in the management of the dual diagnosis.

Table 3 The association of smoking with illness characteristics in subjects with bipolar disorder $(n=70)$

\begin{tabular}{|c|c|c|c|c|c|}
\hline Factor & $\begin{array}{l}\text { Smoking } \\
\text { status }\end{array}$ & $\mathrm{N}$ & Median & IQR & p-value \\
\hline Total & Yes & 37 & 6 & 5 & \\
\hline $\begin{array}{l}\text { No. of } \\
\text { Episodes }\end{array}$ & No & 33 & 4 & 3 & $0.011^{*}$ \\
\hline $\begin{array}{l}\text { Episodes } \\
\text { With } \\
\text { psychotic } \\
\text { symptoms }\end{array}$ & Yes & 37 & 2 & 1.5 & $<0.001^{* *}$ \\
\hline $\begin{array}{l}\text { Episodes } \\
\text { requiring } \\
\text { hospitalisation }\end{array}$ & Yes & 37 & 5 & 1 & $<0.001^{* *}$ \\
\hline
\end{tabular}

${ }^{*} \mathrm{P}<0.05 .{ }^{* *} \mathrm{P}<0.001$

Table 4 The correlation of smoking status with suicide attempt in subjects with bipolar disorder $(\mathrm{n}=70)$

\begin{tabular}{lccc}
\hline Smoking & \multicolumn{2}{c}{ Suicide attempt } & \multirow{2}{*}{ p-value } \\
\cline { 2 - 3 } status & Yes & No & \\
\hline Yes & $13(35.1 \%)$ & $24(64.9 \%)$ & \multirow{2}{*}{0.056} \\
No & $5(15.3 \%)$ & $28(84.8 \%)$ &
\end{tabular}

Chi- square value-3.65

In this study, no significant association was observed between smoking status and bipolar affective disorder with the normal population. The finding is not in agreement with some of the previous studies. ${ }^{2,11,12,13}$ No significant correlation was seen between Fagerstrom nicotine scale score and use of other psychoactive substance in subjects with bipolar disorder or the control group, unlike some of the previous studies. ${ }^{14,15,16}$ Also, no statistically significant correlation was found between Fagerstrom nicotine scale score with Rapid cycling and Chronic medical illness in subjects with bipolar disorder. Kupfer D J et al. had found that diabetes mellitus and cardiovascular diseases were the most common comorbid medical conditions in bipolar patients, and significant association was established between both. ${ }^{17}$

Table 5 The Comparison of years of tobacco use in the two groups (subjects with bipolar disorder $(n=37)$ and the control group $(n=36)$ using independent t-test

\begin{tabular}{ccccc}
\hline Factor & $\mathrm{N}$ & Mean(years) & $\begin{array}{c}\text { Std. } \\
\text { Deviation }\end{array}$ & P-value \\
\hline Bipolar & 37 & 23.32 & 16.447 & $0.016^{*}$ \\
Normal & 36 & 13.47 & 8.561 & \\
\hline * $<0.05$ is significant. $\mathrm{t}=3.2$ & &
\end{tabular}

In the current study, a significant correlation was observed between smoking and total episodes of the disorder and episodes with psychotic symptoms like delusions, hallucinations or catatonic symptoms and episodes requiring hospitalisation in subjects with bipolar disorder. The finding is similar to the finding by Corvin et al. They also found that the rate and intensity of smoking predict the intensity of psychotic symptoms. ${ }^{18}$ Anatoley et al. has also reported that $56.3 \%$ of subjects with bipolar disorder who were smokers had a history of psychotic episodes previously. ${ }^{6}$ However, Cassidy $\mathrm{F}$ et al. had a similar study with bipolar affective disorder and did not find an association between smoking and psychotic symptom. ${ }^{14}$ In the current study, the above finding is supported by the evidence linking the increased release of dopamine by nicotine. Nicotine could cause a change in the dopamine system through induction of supersensitivity of $\mathrm{D} 2$ receptors, which has been proposed as an explanatory mechanism for several risk factors for schizophrenia and as a common pathway for psychotic symptoms. ${ }^{19}$

Ostacher M J et al. had found tobacco smoking to be independently associated with suicide attempts in individuals with bipolar disorder, and current cigarette smoking is a predictor of current and nine-month suicidal ideation and behaviour in bipolar disorder. ${ }^{20}$ Our findings are also similar, although the relationship failed to reach statistical significance. The significant correlation observed between smoking tobacco, and suicide may be because many socio-environmental 
circumstances exacerbate the risk for suicide, such as poor communications, stress and adverse life events. ${ }^{21}$

In this study, the mean years of tobacco use were found to be higher in subjects with bipolar disorder in comparison to the normal population. Thomas $\mathrm{D}$ et al. has found some data indicating less readiness to quit smoking tobacco amongst bipolar patients in India. ${ }^{15}$ George TP et al. showed that people with bipolar disorder have much lower quit rates than smokers without a comorbid condition. ${ }^{22}$ They also suggested that the alternating mood fluctuations may contribute to differences in smoking cessation rates found in bipolar disorder. The study finding here was probably because the majority of smokers were found in the group with bipolar disorder and also as the percentage of successful cessation of smoking is less in subjects with bipolar disorder rather than normal population according to literature. The finding can also possibly be attributed to a lesser awareness of the health risks of tobacco smoking in subjects with bipolar Disorder in Indian set up.

There were some limitations for the study. No structured proforma was used to identify previous episodes. Also, previous health records of most of the patients were not accessible. No structured proforma like DIGS was used for assessing family genetic history. A structured instrument was not used for conclusive ruling out other psychiatric co-morbidities, including other substance abuse disorders in the subjects having bipolar disorder and also to confirm the absence of psychiatric disorder in control subjects. The findings of the study cannot be applied to a larger population as it was a hospital-based study.

\section{CONCLUSION}

In this study, an attempt has been made to understand the relationship between smoking tobacco and bipolar affective disorder compared to the normal population. Association of the sociodemographic and clinical variables with smoking in patients with bipolar affective disorder were also looked into. The mean years of tobacco use were higher in subjects with bipolar disorder in comparison to the normal population. However, no significant association of smoking status was observed between the groups. The study also highlights the significant correlation between smoking and total episodes of the disorder, episodes with psychotic symptoms and episodes requiring hospitalisation in subjects with bipolar. The study also reveals a possible association between smoking and previous suicide attempts in subjects with bipolar disorder. Thus, a better understanding of the dual diagnosis and intervention for it is required for better prognosis of the disorders. The relationship between tobacco smoking tobacco and bipolar disorder may be bidirectional, and that cause and effect may be difficult to determine. In future, more research on the biologic link between smoking and bipolar disorder will help in the development of new medications that can treat both disorders at the same time in this socio-cultural context.

\section{Financial support and sponsorship}

Nil

\section{Conflicts of interest}

None declared

\section{REFERENCES}

1. Fiore MC, Jaen C R. A clinical practice guideline for treating tobacco use and dependence: a US Public Health Service report. Am J Prev Med.2008 Aug;35(2): 158-76.

2. Hughes JR, Hatsukami DK, Mitchell JE, Dahlgren LA. Prevalence of smoking among psychiatric outpatients. Am J Psychiatry 1986;143(8): 993-7.

3. Waxmonsky JA, Thomas MR, Miklowitz DJ, Allen MH, Wisniewski SR, Zhang $\mathrm{H}$, et al. Prevalence and correlates of tobacco use in bipolar disorder: data from the first 2000 participants in the Systematic Treatment Enhancement Program. Gen Hosp Psychiatry 2005;27(5): 319-20.

4. Chang CK, Hayes RD, Broadbent M, Fernandes AC, Lee W, Hotopf M, et al. All-cause mortality among people with serious mental illness (SMI), substance use disorders, and depressive disorders in southeast London: a cohort study. BMC Psychiatry. 2010;10: 77. Accessed from: https://doi.org/10.1186/1471-244X-10-77

5. Heffner J L, Strawn J R, Del Bello MP, Strakowski SM, Anthenelli R M. The Co-occurrence of Cigarette Smoking and Bipolar Disorder: Phenomenology and Treatment Considerations. Bipolar Disorder. 2011 AugSep; 13(5-6): 439-53.

6. Anatoly K, Dmitri N, Rabinowitz D. Association between tobacco smoking and bipolar affective disorder: clinical, epidemiological, cross-sectional, retrospective study in outpatients. Compr Psychiatry. 2012. 53(3); 269-74.

7. World Health Organization. The ICD-10 classification of mental and behavioural disorders: ICD-10; clinical descriptions and diagnostic guidelines. Geneva: World 
Health Organization; $1992.362 \mathrm{p}$.

8. Montgomery SA, Asberg M. A new depression scale designed to be sensitive to change. Br J Psychiatry 1979; 134: 382-89

9. Young RC, Biggs JT, Ziegler VE, Meyer DA. A rating scale for mania: reliability, validity and sensitivity. $\mathrm{Br} \mathrm{J}$ Psychiatry 1978; 133(5): 429-35

10. Dijkstra A and Tromp D: Is the FTND a measure of physical as well as psychological tobacco dependence? J Subst Abuse Treat 2002; 23(4):367-74

11. Gonzalez-Pinto A, Alberich S, Barbeito S, Alonso M, Vieta E, Martinez-Arán A, et al. Different profile of substance abuse in relation to predominant polarity in bipolar disorder: the Vitoria long-term follow-up study. J Affect Disord 2010;124(3): 250-5.

12. Swann AC. Bipolar disorder and substance abuse: two disorders or one? J Dual Diagn 2005;1(3): 9-23.

13. McEachin RC, Saccone NL, Saccone SF, KleymanSmith YD, Kar T, Kare RK, et al. Modeling complex genetic and environmental influences on comorbid bipolar disorder with tobacco use disorder. BMC Med Genet 2010;11: 14.

14. Cassidy F, Ahearn EP, Carroll BJ. Substance abuse in bipolar disorder. Bipolar Disord 2001: 3(4): 181-88.

15. Thomson D, Micheal B. Tobacco use in Bipolar Disorder. Clin Psychopharmacol Neuroscience. 2015 Apr; 13(1): 1-11.
16. Grucza RA, Bierut LJ. Cigarette smoking and the risk for alcohol use disorders among adolescent drinkers. Alcohol Clin Exp Res 2006;30(12): 2046-54

17. Kupfer D J. The Increasing Medical Burden in Bipolar Disorder. JAMA 2005; 293(20):2528-30

18. Corvin A, O'mahony E, O'regan M, Comerford C, O'connell R, Craddock R, et al. Cigarette smoking and psychotic symptoms in bipolar affective disorder. $\mathrm{Br} \mathrm{J}$ Psychiatry 2001;179: 35-8.

19. Li-Shiun Chen, Hong Xian, Richard A. Grucza. Nicotine Dependence and Comorbid Psychiatric Disorders: Examination of Specific Genetic Variants in the CHRNA5-A3-B4 Nicotinic Receptor Genes, Drug Alcohol Depend.2012 Jun; 123 Suppl 1: S42-S51

20. Ostacher M J, LeBeau R T, Perlis R H, Andrew A N, Hannah G L, Samantha J M, et al. Cigarette smoking is associated with suicidality in bipolar disorder. Bipolar Disord. 2009 Nov;11(7): 766-71.

21. Simon GE, Hunkeler E, Fireman B, Lee JY, Savarino J. Risk of suicide attempt and suicide death in patients treated for bipolar disorder. Bipolar Disord. 2007;9(5):526-30.

22. George TP, Wu BS, Weinberger AH. A review of smoking cessation in bipolar disorder: Implications for future research. J Dual Diagn. 2012;8(2): 126-30. 